\title{
RODOVIA EM UNIDADE DE CONSERVAÇÃO: O CASO DO PARQUE ESTADUAL DO MORRO DO DIABO, SÃO PAULO, BRASIL.
}

Helder Henrique de Faria ${ }^{1}$ Andréa Soares Pires ${ }^{2}$

\begin{abstract}
Resumo: A rodovia SP-613 segmenta o Parque Estadual do Morro do Diabo e constitui-se numa grande fonte de distúrbios à fauna e flora da área. Por este motivo, desde 1989 tem-se realizado pesquisas e ações de gestão visando a diminuir os impactos negativos constatados por meio do monitoramento, tendo como ancoras deste processo a legítima participação da sociedade, representada no Conselho Consultivo da área, e o envolvimento proativo de organizações sensíveis e afins a este tema ambiental. A discussão, originalmente circunscrita ao meio técnico, virou assunto de interesse comunitário, obrigando o ministério público a defender os interesses difusos representados pela perda de vida silvestre e apontando para a necessidade de maior sinergia entre as organizações diretamente envolvidas com essa ameaça. Após muitos pleitos e diligências, ação civil pública, processo de licenciamento, ampla divulgação dos fatos pela mídia e a apresentação do problema diretamente à secretaria de meio ambiente de São Paulo, veio a edição do Decreto Estadual № 53.146, de 20 de junho de 2008, que define os parâmetros para a implantação, gestão e operação de estradas no interior de unidades de conservação de proteção integral. Desdobramentos deste diploma legal incidem hoje sobre a gestão do trecho da rodovia que se sobrepõe ao parque estadual, um avanço significativo na gestão da ameaça, mas não a sua completa solução.
\end{abstract}

\footnotetext{
${ }^{1}$ Eng. Florestal, pesquisador do Instituto Florestal/SMA. MMADRE-Unoeste. helderdefaria@gmail.com

${ }^{2}$ Bióloga, pesquisadora do Instituto Florestal/SMA.deapires@yahoo.com.br
} 


\section{Introdução}

Ameaças e conflitos sócio-econômicos e ambientais permeiam as unidades de conservação (UC) desde que estas foram idealizadas e surgiram no espaço geográfico construído pelo homem, em 1972 (Diegues, 1996). A definição de ameaças às áreas protegidas passa por diversas controvérsias, mas a que nos parece mais adequada é dada por Machelis \& Neumann (1986): “ameaças são as condições de origem humanas ou naturais que causa um dano significativo aos recursos protegidos, ou então aquelas que contrariam os objetivos, o manejo e a administração das unidades de conservação".

$\mathrm{Na}$ atualidade se reconhece que a maior ameaça ao sistema de áreas protegidas e aos sistemas de suporte à vida do nosso planeta esta relacionada aos fatores que desencadeiam as mudanças climáticas globais, entretanto, outros fatores de ameaças estão plasmados e materializados dentro e fora das UCs e são alvo de distintos estudos e medidas de manejo técnico.

Um estudo abrangendo 48 UCs da Amazônia detectou que 46\% daquelas áreas continham obras de infra-estrutura oriundas de projetos setoriais em conflito com os objetivos das mesmas (Araujo e Barreto, sd). Faria, Pires e Zanchetta (2005) classificaram as ameaças em dois grandes grupos: as ameaças internas oriundas do próprio sistema gerencial, e as ameaças externas, definidas pela ação ou existência de agentes exógenos ao sistema gerencial. Dentre tantas ameaças às UCs do estado mais rico da nação, os resultados apontaram um novo fator exógeno de dano biológico até então não considerado pelos gestores paulistas, a ocorrência de impactos causados por estradas de rodagem, notadamente em importantes unidades como os parques estaduais Jacupiranga, Vassununga, Serra do Mar, Morro do Diabo dentre outros.

A construção de estradas é um mecanismo de fragmentação da paisagem de alto impacto, muito embora sejam concebidas com significância econômica e social como corredores de transporte e utilidades. Existem estudos que explicitam os efeitos dessas intervenções nas paisagens naturais, a fragmentação de habitats, perturbação dos hábitos faunísticos, invasão de espécies, efeitos de borda, erosão, poluição atmosférica e hídrica, etc. (Van Der Zande et al., 1980; Amaranthus et all, 1985; Schonewald-Cox \& 
Buechner, 1991; Lopes e Queiroz, 1994; Philcox et al., 1999; Haskell, 2000; Jones et all., 2000; Faria \& Moreni, 2000; Trombulak e Frissel, 2000; Parendes e Jones, 2000; Forman e Deblinger, 2000; Clevenger e Waltho, 2000; Scoss \& Junior, 2000; Candido-Jr et al., 2002; Rodrigues et al., 2002; Smith \& Dodd, 2003; Lamy, Leuzinger e Pinto, 2006; SEMAMT, 2007).

Relativo ao monitoramento de danos à biota, no Brasil os efeitos sobre a fauna tem sido o fenômeno mais preocupante e estudado, talvez porque seja o mais freqüentemente observável, fácil de obter dados e, notadamente, o que mais impacta os sentimentos humanos, apesar dos incêndios nas imediações das estradas brasileiras poderem ocasionar efeitos de magnitude elevada. Milli e Passamani (2006), por exemplo, apresentam dados oriundos de estudos dessa natureza, com trabalhos efetuados nos estados brasileiros do Rio Grande do Sul, Paraná, São Paulo e Minas Gerais. No Brasil, a temática dos impactos ambientais causados por rodovias ganhou espaço e é foco de um evento realizado anualmente, o RoadEcology organizado pela Universidade Federal de de Alfenas (http://www.dbi.ufla.br/reb2011/).

Há que se considerar, entretanto, que o trecho de uma rodovia dentro de uma unidade de conservação pode abrigar grande potencial paisagístico, podendo vir a ser mais um atrativo à visitação pública e à valorização da área. Tanto que no Brasil os estudos primordiais materializados no Plano do Sistema de Unidades de Conservação do Brasil, II Etapa (Pádua et all, 1982), que precederam ao atual SNUC (Brasil, 2000), propuseram a categoria de manejo "estrada parque" definindo-a como uma "unidade de conservação linear de alto valor educativo, cultural e recreativo que visa proteger a paisagem ao longo das vias de acesso, cujos limites são estabelecidos com vistas à proteção de suas características e mantidos em estado natural ou semi-natural, evitandose intervenções que desfigurem a estética da paisagem'.

Dourojeanni (2003) defende a criação de 'estradas parque' por considerar que esta categoria auxiliaria os países latinoamericanos a fomentar o turismo, criaria oportunidades para a economia local e reduziria os riscos de acidentes, categoria que não teria o objetivo primário de conservar, mas sim de proteger paisagens e belezas cênicas vistas da estrada. 


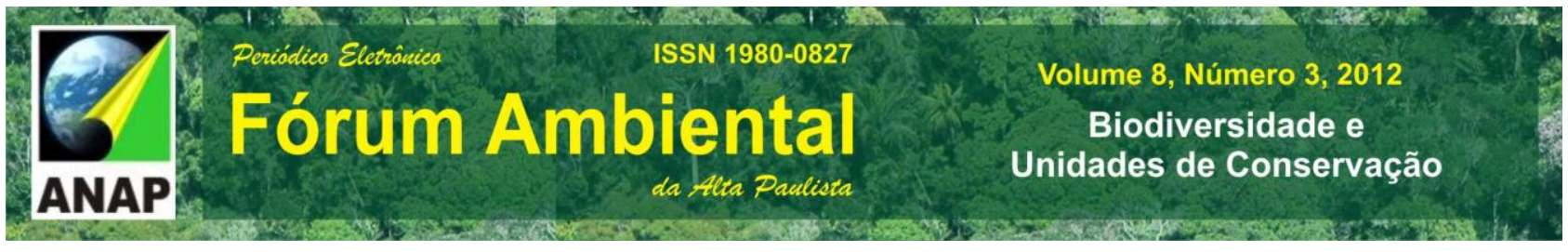

No ano 2000 publicamos um artigo no qual relatamos os problemas produzidos pela rodovia incrustada no PE Morro do Diabo, os dados de monitoramento dos impactos e as possíveis soluções (Faria e Moreni, 2000). Passados doze anos daquela publicação, nossa pretensão é atualizar o assunto e apresentar os fatos e os resultados obtidos na gestão deste tema, considerado um dos grandes fatores de ameaça a esta unidade de conservação da natureza.

\section{O Parque Estadual do Morro do Diabo e a SP-613}

O Parque Estadual do Morro do Diabo - PEMD localiza-se entre as coordenadas geográficas $22^{\circ} 27^{\prime}$ a $22^{\circ} 40^{\prime}$ de Latitude S e $52^{\circ} 10^{\prime}$ a $52^{\circ} 22^{\prime}$ de Longitude W, no município de Teodoro Sampaio, São Paulo. Seus 33.845,33ha guardam a maior amostra de Floresta Semi Decídua do estado. É gerenciado pela Fundação para a Conservação e a Produção Florestal do estado de São Paulo - FF.

Em 1970, quando da abertura de $14 \mathrm{Km}$ de rodovia dentro da Reserva do Morro do Diabo, estudos dos impactos ambientais causados por estes empreendimentos eram desconsiderados, senão tidos como opositores ao desenvolvimento e ao governo, ainda que os efeitos gerados fossem de elevada magnitude (IF, 2006). A SP-613 é uma rodovia que se enquadra no Sistema Arterial Primário, pista única de dois sentidos de tráfego, que dá vazão à rodovia SP-563 e acesso aos estados do Paraná e Mato Grosso do Sul, além de atender os municípios de Teodoro Sampaio, Euclides da Cunha, Rosana, e as Usinas Hidroelétricas de Primavera e Taquaruçu. A intensidade de tráfego fica abaixo de 5.500 veículos/dia, mas é muito utilizada por veículos pesados (DER, 2008), responsáveis por grande parte da mortandade de animais silvestres.

Um monitoramento efetuado por 10 anos contabilizou 182 indivíduos mortos por atropelamento, dentre 25 espécies identificadas. Destes, $16 \%$ ou 29 animais eram de espécies ameaçadas de extinção (Faria e Moreni, 2000), mas os autores ponderam que a falta de recursos para custeio impediu que se efetuasse o levantamento com maior rigor, tanto que alguns anos apresentaram quantidades muito pequenas de registros.

Para Milli e Passamani (2006) o número de mortes registradas é certamente uma sub-estimativa, pois vários animais ao colidirem com os veículos caem fora da estrada ou 
conseguem ainda se locomover para um lugar mais abrigado, vindo a morrer sem serem detectados nas amostragens (Rodrigues et al., 2002). Ainda, aqueles de pequeno porte, podem ser facilmente retirados do asfalto por animais carniceiros, como o cachorro do mato (Cerdocyon thous) e carcarás (Polyborus plancus) sem que seja possível o registro, como mostra o trabalho de Candido Jr et.al. (2002).

Tendo por base os 182 animais encontrados no período e as premissas acima elencadas, pesquisador em visita ao Parque realizou uma extrapolação estatística utilizando estatísticas não paramétricas e obteve que o número estimado de animais mortos poderia alcançar a assustadora cifra de até 993 indivíduos em 10 anos, uma média de 100 por ano (Walter Barrella, 2002, comunicação pessoal).

Considerando que no Morro do Diabo ocorre endemismo aliado à restrição geográfica, o argumento de que a estrada funcionaria como um regulador de populações, proposto por Valladares-Padua et. al. (1995) é refutado já que esta técnica nunca é utilizada de forma aleatória. Típicos exemplos são a eliminação de indivíduos da espécie mico-leão-preto (Leontophitecus chrysopygus), primata que no PEMD possui sua maior população livre na natureza, e o maior felino das Américas, a onça pintada (Panthera onca). Mesmo por que no PEMD é flagrante que a rodovia elimina mais espécimes animais que a caça em sí, corroborando o afirmado por Formam e Alexander (1998).

Freire e Mello (2008) estudaram os impactos da rodovia sobre o PEMD e distinguiram 32 tipos diferentes de fatores negativos, separando-os entre as fases de implantação e operação e classificando o grau de importância como baixo, médio, alto e muito alto. O único na classe muito alta foram os atropelamentos de animais silvestres; os considerados de importância alta foram a fragmentação de habitats, alteração no relevo do terreno, facilitação para a invasão de espécies exóticas, riscos de incêndio, presença de ruídos, alteração na distribuição dos animais e lançamento de resíduos e acidentes com produtos perigosos.

Os mesmos autores efetuaram a valoração dos animais atropelados tendo por base uma amostra de 119 estudantes universitários e cinco espécies de animais silvestres para cujas populações havia estimativas oriundas de pesquisa (Leontopithecus chrysopygus, Leopardus pardalis, Panthera onça, Puma concolor e Tapirus terrestris). Utilizando o método "Análise da Disposição de Pagar" alcançaram cifras que justificam a 
importância e relevância social dos custos das medidas destinadas a mitigar os impactos da rodovia.

\section{Gestão da ameaça: ministério público e educação}

Considerando a conceituação defendida por SANTOS (2010), para se 'proteger' uma unidade de conservação são necessários poucos requisitos, como o diploma legal de criação, limites bem definidos e atividades de vigilância. Mas para se 'conservar' a mesma área à posteridade outros componentes são imprescindíveis ao sistema gerencial, tais como a pesquisa científica, a educação ambiental; forte elemento de psicologia humana para dirimir assuntos atinentes às relações interpessoais dos funcionários; relações públicas com os vizinhos e lideranças locais/regionais; interação com organizações locais e regionais, forte noção de planejamento e de legislação ambiental, entre outras infindáveis variáveis dependentes das particularidades locais (Faria e Pires, 2007).

Ou seja, para se conservar é necessário mais ações que simplesmente aquelas para se proteger. É necessário se fazer gestão, aqui considerada como sendo 0 equilibrado planejamento, coordenação e controle dos componentes políticos, técnicos e operacionais e os diversos atores sociais que incidem sobre o desenvolvimento da área, de maneira a obter-se a eficácia requerida para serem atendidos os objetivos que norteiam a existência da unidade de conservação e a manutenção da produtividade dos ecossistemas por ela abrangidos (Faria, 2004).

A travessia de animais silvestres por obstáculos físicos, como uma rodovia, correlaciona-se a diferentes necessidades como migração, procura de alimento, acasalamento ou simplesmente a ocupação de territórios, convergindo em constantes atropelamentos e perdas de espécimes (Lima e Obara, 2004; Jochimsen, 2006), um fato rotineiro no PEMD.

A Constituição da República do Brasil de 1988 não havia completado seu primeiro aniversário e o Ministério Público Estadual - MPE estava engatinhando em suas novas atribuições frente ao povo brasileiro; e os cidadãos ainda não estavam acostumados em participar e discutir os assuntos de interesse coletivo, ainda mais questões ambientais 
que afligiam 'bichos do mato'. Ao assumir a condução do processo o MPE catalisou as discussões sobre um tema novo, gerando forte entusiasmo nas representações sociais participantes. Instaurou-se um Inquérito Civil para apurar as causas, conseqüências e os responsáveis pelos atropelamentos de animais silvestres no parque e este assumiu 0 compromisso de promover o monitoramento dos fenômenos adversos que ocorressem no trecho da SP-613 dentro da UC.

O inquérito transformou-se na Ação Civil Pública GAEMA-PP 1.519/2000, em que o poder público exige que o DER cumpra as seguintes medidas:_Instalação de redutores eletrônicos de velocidade nos pontos críticos com maiores índices de atropelamentos, num total de 4 dispositivos; _instalação de comunicação visual que chame atenção dos motoristas para o problema; _passagens subterrâneas; _fazer manutenção dos aceiros corta fogo às margens da rodovia.

A ação foi julgada procedente, porém a justiça entendeu não poder arbitrar as medidas que o órgão executivo devesse fazer, cabendo ao DER estipular as obras ou atividades a serem desenvolvidas. O DER interpôs recurso no Tribunal de Justiça por discordar da condenação imposta pelo juiz de primeira instância. Por sua vez, o MPE também interpôs recurso, por entender que o juiz deveria ter especificado as ações a serem implementadas como forma de proteger a fauna local e não deixar, de forma genérica, para o DER defini-las.

Segundo matéria publicada em jornal de circulação regional “o Tribunal de Justiça acolheu o recurso do Ministério Público Estadual e o DER teria que implementar radares fotográficos fixos ao longo da Rodovia, passagens subterrâneas e aceiramento da faixa de domínio" (Oeste Notícias, 2009). A partir daí os custos de periodicamente se fazer aceiros corta-fogo na rodovia foram assumidos pelo DER; as passagens subterrâneas existentes foram monitoradas e analisadas sua eficácia; foram instaladas sinalização convencional e especial; convencionou-se a velocidade máxima no trecho (70 $\mathrm{Km}$ ), aumentou-se a fiscalização de velocidades e as campanhas educativas na rodovia.

Essas campanhas, realizadas pelo parque, contam com o apoio das policias rodoviária e ambiental e em algumas oportunidades são integradas por grupos estudantis locais. No limite do parque e rodovia monta-se uma tenda na qual são dispostos animais taxidermizados atropelados; os usuários recebem materiais educativos sobre o bom uso 
da rodovia, os problemas existentes e informações sobre o parque. Os espécimes empalhados chamam atenção de todos, em especial das crianças, que se regozijam e tiram fotos.

As palestras sobre o tema sempre são impactantes, pois se trata de mostrar as mortes que a rodovia causa. Entretanto, na medida em que se avança são expostas as soluções, as oportunidades e os benefícios que uma rodovia bem planejada pode trazer à determinada localidade. As palestras são concluídas com a apresentação de um material audiovisual ${ }^{3}$ produzido na Europa, no qual animais silvestres são catapultados sobre uma moderna alto-estrada, película que descontrai o ambiente e provê engajamento aos ouvintes.

Aliado a isso a equipe do programa de uso público adotou uma idéia do zoológico de Sorocaba e implantou um mini 'cemitério dos atropelados' na sede da unidade, próximo ao museu natural que contem os animais taxidermizados. A integração de informações descontraídas para a mudança de atitudes é muito bem recebida pelos visitantes. Contudo, a estratégia considerada a mais eficaz não foi implementada, que é a instalação dos redutores de velocidade nos pontos críticos apontados pelo monitoramento.

\section{Informação, sensibilização e políticas públicas}

O monitoramento efetuado no PEMD (Faria e Moreni, 2000) revelou importantes informações para a gestão ambiental daquele trecho da rodovia SP-613, como as espécies da fauna mais susceptíveis aos atropelamentos, períodos do dia, do ano e locais com maiores frequências de acidentes, permitindo sugerir ao órgão responsável algumas medidas para mitigar os seus impactos. Aquelas informações foram relevantes também

\footnotetext{
${ }^{3}$ Material disponível em:

http://www.google.com.br/url?sa=t\&rct=j\&q=animals\%20jumping\%20highway\&source=video\&cd=1\&ved=0C DgQtwlwAA\&url=http\%3A\%2F\%2Fwww.youtube.com\%2Fwatch\%3Fv\%3DBfoO6zThyc\&ei=rO5hT9rBJlesgwfTu7XJAg\&usg=AFQjCNHeEPmI1IRVOfjC_Qg50E2hjDLTZg
} 
para o planejamento da unidade, quando se definiu que aquele trecho da rodovia seria a Zona de Uso Conflitante (ZC).

Considerada um elemento antrópico de significativa importância ao desenvolvimento sócio-econômico regional, o objetivo de gestão da ZC é o estabelecimento de estratégias que minimizem os impactos sobre os recursos naturais, com normas muito claras para a busca de soluções juntamente com os empreendedores ou organismos responsáveis (IF, 2006).

A partir de 2002 os animais silvestres vertebrados atropelados no interior do PEMD foram registrados na forma de Boletins de Ocorrência, enquadrados na Lei de Crimes Ambientais, 9.605/1998, junto à Delegacia de Polícia Civil de Teodoro Sampaio; e a partir de 2005 as ocorrências passaram a ser georreferenciadas e inseridas em um sistema de informações geográficas associado a banco de dados digital. De setembro de 2002 a dezembro de 2010 contabilizou-se 55 animais registrados; desses as maiores vítimas foram antas Tapirus terrestris (13), cachorros do mato Cerdocyon thous (14), quati nasua nasua (6), veados Ozotocerus bezoarticus (4), onça panthera onca (3) e jaguatiricas Felis pardalis (2).

Um estudo sobre o atropelamento de antas (Tapirus terrestris) na SP-613 aponta que o impacto ambiental sobre a população desta espécie será drástico caso não sejam adotadas medidas que paralisem este processo (Médice, 2010). Esta autora aplicou uma modelagem matemática considerando uma população de 126 indivíduos no PEMD, uma média de seis indivíduos mortos por ano e a taxa de natalidade, que gira em torno de 1,63 animais/ano e concluiu que este nível de atropelamentos levaria a população de antas à extinção local em 38 anos. Sendo a espécie um animal extremamente importante para a dinâmica florestal, principalmente porque é grande dispersor de várias espécies de árvores, pode-se inferir sobre o desastre que seria tal fenômeno para a floresta em si.

Em 2007 o DER implantou alambrados laterais em sete passagens tubulares existentes sob a rodovia. Essas passagens foram uma exigência do gestor do Parque à época da construção da rodovia, em 1970, visando prover aos animais silvestres alguma rota alternativa para transpor a estrada (Garrido, 1974). Naquela época não haviam estudos ecológicos para elucidar o melhor designe para estas passagens, pois as mesmas precisam atender a uma diversificada fauna com diferentes necessidades e 
hábitos. Por exemplo, no Canadá, Clevenger e Waltho (1999) revelaram que há uma certa preferência de ungulados por túneis de grande extensão e pequena abertura, com altura máxima de 2,4m e largura máxima de 7 metros. Em outros casos, algumas espécies podem apresentar fobia a ambientes muito abertos, sensibilidade ao excesso de iluminação ou baixa umidade (Olmos, 1996), tornando necessário o uso de camuflagens com a vegetação.

Após a implantação dos alambrados visando conduzir a fauna para as passagens, empreendeu-se o monitoramento das pegadas dos animais que ali circulavam, revelando que poucas espécies utilizam de fato esses túneis, maiormente pequenos mamíferos; fauna de médio e grande porte, como veados e antas não se utilizam destas passagens (Olmos, 1996), mesmo porque foram observadas pegadas de predadores como jaguatiricas e onças nas proximidades, cujo simples odor inibe a passagem de herbívoros. Essas observações demonstraram a ineficácia que tais investimentos resultariam se levados adiante.

Outra iniciativa proposta pelos engenheiros rodoviários foi a instalação de refletores "desencorajadores" de animais, que consiste em uma peça de plástico vermelho fixado na lateral da estrada, rente ao acostamento, cuja disposição reflete a luz dos faróis e emite um facho de luz vermelha em direção à mata contígua, sinal que espantaria os bichos para longe do perigo. Após seis meses de instalados quase $100 \%$ dos dispositivos foram furtados, o que efetivamente não fez falta, pois os mesmos não impediam que os animais atravessassem a rodovia.

A solução para a transposição de primatas e outras espécies arborícolas ainda é polêmica. Para o Parque, onde a rodovia é asfaltada e a largura efetiva do conjunto estrada-acostamento-aceiro chega aos 50 metros, os efeitos de borda são mais amplos e intensos. Segundo Schonewald Cox \& Buechner (1991), os efeitos de uma rodovia podem estender-se, causando danos à fauna, por até $600 \mathrm{~m}$ no interior da floresta. Inferindo-se que uma ponte para travessia aérea eficaz deva ir além da área de tensão ecológica, isto implicaria num acesso de dimensões consideráveis, sendo que a construção de várias passagens poderia iniciar um novo efeito de borda em menor escala, mas com provavelmente os mesmos sintomas, havendo então implicações contrárias ao método. 
O assunto deste artigo ganhou novas proporções a partir do momento em que escalões superiores do estado se tornaram sensíveis ao tema, fazendo do 'Morro do Diabo' o primeiro case de outros que os sucederam.

Entendido o problema, resolveu a Secretaria de Meio Ambiente aproveitar a oportunidade e estender $\mathrm{o}$ alcance das medidas para o 'sistema' inteiro, a partir da elaboração e edição do Decreto №53.146, de 20 de junho de 2008, que define os parâmetros para a implantação, gestão e operação de estradas no interior de unidades de conservação de proteção integral no Estado de São Paulo, comumente conhecido como 'decreto estrada parque', muito embora não exista esta categoria de manejo no estado. Este decreto prevê que o órgão, entidade ou empresa, pública ou privada, responsável diretamente pela implantação e operação da estrada pública inserida em unidade de conservação de proteção integral, deve providenciar um Plano de Implantação e um Plano de Gestão e Operação para cada trecho de estrada.

Quase que concomitante, o DER executou um 'projeto de comunicação visual' com novas placas educativas e portais nas extremidades do trecho, sinalizando os limites do parque na rodovia, de modo que os usuários soubessem que estavam atravessando um lugar especial. A inauguração dessas instalações anunciou também o início dos trabalhos entre as secretarias de estado visando a elaboração das propostas para os planos de implantação e operação previstos pelo decreto já citado.

Ambos os planos foram apresentados, discutidos e ratificados pelo Conselho Consultivo do parque, culminando na edição de uma resolução conjunta entre a Secretaria de Meio Ambiente e a Secretaria de Transportes, publicada no diário oficial do estado em 21 de julho de 2011 e resumidos no quadro 2. 
Quadro 2. Responsabilidades assumidas e compartilhadas entre o DER e a Fundação Florestal no trecho compreendido entre o km 5+900 e o km 19+900 da rodovia SP-613 ${ }^{4}$.

> Manutenção preventiva e sistemática das margens da rodovia (DER);

> Instalação e manutenção de quatro dispositivos de controle de velocidade, nos pontos críticos de maior atropelamento de animais silvestres, de conformidade com os levantamentos efetuados pelo PEMD (DER);

$>$ Instalação e manutenção, de acordo com as Normas pertinentes do DER, de sinalização para a sensibilização dos usuários da rodovia, conforme projeto a ser apresentado pela administração do Parque (FF/DER);

> Plantio de "ilhas" de vegetação, nas laterais dos aceiros e da rodovia, para posterior implantação e manutenção de 'pontes' para mamíferos arborícolas entre os dois fragmentos do Parque, nos sítios da SP-613 em que esta medida seja possível (FF/DER);

> Manutenção e sinalização das estruturas dos Portais localizados nos km 5+900 e no km 19+900 (DER);

> Elaborar Portaria limitando o peso máximo permitido na Rodovia SP-613, visando coibir veículos com tonelagem excessiva (DER);

> Manutenção dos sistemas de drenagem da rodovia (DER);

> Instalação de placas de sinalização, de acordo com as Normas pertinentes do DER, indicando a existência e localização do PEMD, nas confluências das rodovias que dão acesso ao município de Teodoro Sampaio, priorizando-se os trevos de Presidente Prudente, Presidente Venceslau, Rosana, Presidente Epitácio e UHE Taquaruçu (DER);

> Projeto e instalação de Área de Descanso para motoristas, de maneira tal que os mesmos tenham local adequado de parada e alimentação, evitando-se o uso das margens da estrada no interior do Parque e que conduz à contaminação por lixo e diminuição do valor estético da paisagem (DER);

> Projeto e instalação de 'estacionamento rústico' na base do Morro do Diabo, na faixa de domínio do DER, facilitando acesso à trilha homônima (DER);

$>$ Operação dos pontos de fiscalização com radares estáticos (DER);

> Realização de campanhas de sensibilização aos usuários (FF/DER);

> Monitoramento da eficácia das medidas adotadas resultantes da adequação da SP613 (FF/DER);

> Elaborar Planos de Contingência para solução de ocorrências geradas a partir de acidentes envolvendo cargas perigosas, envolvendo animais silvestres, pessoas e incêndios (DER);

D Elaboração de relatórios periódicos a respeito das ocorrências registradas na estrada (volume de trafego, multas aplicadas, ocorrências de acidentes com animais e usuários, ocorrências de incêndios, cargas perigosas e lixo e materiais diversos recolhidos na estrada) (DER);

> Manter informado o Conselho Consultivo do PEMD, através da sua administração ou nas reuniões deste colegiado, das medidas adotadas pelo empreendedor.

Fonte: D.O.E., 2011.

\footnotetext{
${ }^{4}$ N.a.- Obstáculos físicos como os 'quebra-molas' e os redutores de velocidades, que fazem vibrar os veículos, foram considerados, mas descartados haja vista que os primeiros poderiam colocar em risco vidas humanas e criar uma leva de usuários hostis à medida e ao Parque. Os redutores de velocidade produzem barulho e não são eficazes, pois grande parte dos motoristas não reduz a velocidade.
} 


\section{Conhecimento e licenciamento ambiental}

Concomitantemente a estas iniciativas, e às pressões, o DER deu entrada na documentação exigida para o licenciamento corretivo da rodovia, em face do artigo 34 do Decreto № 4.340/2002: "os empreendimentos implantados antes da edição deste Decreto e em operação sem as respectivas licenças ambientais deverão requerer, no prazo de doze meses a partir da publicação deste Decreto, a regularização junto ao órgão ambiental competente mediante licença de operação corretiva ou retificadora".

O "Estudo Ambiental para Solicitação de Licença de Operação Regularizadora" apresentado faz jus ao Decreto Estadual № 53.146/2008, conhecido no meio como 'Decreto das Estradas Parque de São Paulo', que em seu artigo $2^{\circ}$ estabelece que "o órgão, entidade ou empresa, pública ou privada, responsável diretamente pela implantação e operação da estrada pública inserida em Unidade de Conservação de Proteção Integral, deverá providenciar um Plano de Implantação e um Plano de Gestão e Operação para cada trecho de estrada", que devem atender os preceitos delineados no plano de manejo da unidade, mesmo porque a rodovia é considerada como uma das maiores ameaças à biota do PEMD.

Não é necessário explicitar que os 'Estudos' foram produzidos sob uma base técnica rasa e tendenciosa, aspectos revelados nas análises e considerações emitidas pelos técnicos do parque, que ponderaram a ausência de dois aspectos importantes: _ $O$ custo ambiental acumulado em função das mortes dos animais silvestres e, _a contabilidade dos gases do efeito estufa emitidos no trecho em que a SP-613 secciona o PEMD.

A morte de dois exemplares filhotes de onça parda (Puma concolor), por queimada de cana-de-açúcar no entorno do PEMD resultou um valor de dano ambiental na ordem de $\mathrm{R} \$ 1.724 .451,80$ (Hum milhão, setecentos e vinte e quatro mil, quatrocentos e cinqüenta e um reais e oitenta centavos), segundo as informações contidas no Inquérito Civil № 031/2009, do Grupo de Atuação Especial de Defesa do Meio Ambiente, que tramita na Promotoria de Justiça de Presidente Prudente. Caso a metodologia usada 
neste calculo (Hahn et all., sd) ${ }^{5}$ fosse aplicada à fauna perdida no PEMD em função da rodovia, os valores de danos e compensações poderiam alcançar vultuosas cifras, como a seguir demonstrado.

Desconsiderando a distinção entre as espécies da fauna mortas no interior do PEMD em função da SP-613 e o valor especifico que cada espécie possui no ecossistema para a manutenção de seu equilíbrio dinâmico; desconsiderando as proles que cada fêmea poderia gerar em vida; considerando o valor de cada individuo como sendo o valor unitário alcançado acima, isto é $(R \$ 1.724 .451,80 / 2)=R \$ 862.225,90$ (oitocentos e sessenta e dois mil, duzentos e vinte e cinco reais e noventa centavos); e considerando apenas os indivíduos registrados na forma de Boletins de Ocorrência (56) a partir do ano 2002 o valor do dano ambiental no período pode ser estimado em até $\mathrm{R} \$$ 48.000.000,00 (quarenta e oito milhões de reais).

Caso a rodovia fosse um empreendimento privado certamente o PEMD seria beneficiado com folgada compensação ambiental, que poderia ser revertida para a melhoria da gestão da rodovia e pesquisas mais aprofundadas sobre seus efeitos sobre as comunidades faunísticas do parque, por exemplo.

Por seu lado, um estudo realizado por pesquisadores da EMBRAPA (Soares et.al. 2009) sobre a mitigação das emissões de gases do efeito estufa (GEE) pelo uso do etanol da cana-de-açúcar produzida no Brasil nos proporciona uma comparação entre carros do mesmo modelo e marca, para três tipos de combustível (diesel, gasolina brasileira e etanol), que serviram de base para uma simulação de emissões no trecho da SP-613.

A caminhonete equipada com motor a diesel apresenta consumo médio de $13,5 \mathrm{~km}$ por litro e a caminhonete equipada com motor "total-flex" percorre 10,4 ou 7,2 km para cada um dos combustíveis (WEBMOTORS, 2009 - dados fornecidos pelo fabricante). Utilizando estes valores em uma viagem de $100 \mathrm{~km}$, associados aos dados de emissão de gases do efeito estufa (GEE), obtêm-se os resultados a seguir (Quadro 1).

\footnotetext{
${ }^{5}$ Metodologia desenvolvida no Departamento Estadual de Proteção dos Recursos Naturais Renováveis DEPRN, da Secretaria de Estado do Meio Ambiente de São Paulo, adotada pelo Centro de Apoio Operacional das Promotorias de Justiça de Urbanismo e Meio Ambiente do Ministério Público (CAO-UMA).
} 
Quadro 1: Emissões de GEEs em diferentes veículos em viagem de $100 \mathrm{Km}$

\begin{tabular}{|c|c|c|c|c|c|c|}
\hline Modelo & motor & Combustível & $\begin{array}{c}\text { Rendimento } \\
\mathbf{( K m / L )}\end{array}$ & $\begin{array}{c}\text { Potência } \\
\text { Máxima }\end{array}$ & $\begin{array}{c}\text { GEEs } \\
\text { emitido } \\
\mathbf{k g C O}_{\mathbf{2}}\end{array}$ & $\begin{array}{c}\text { Emissão } \\
\text { evitada } \\
(\%)\end{array}$ \\
\hline S10 & 2.8 turbo & Diesel & 13,5 & $140 \mathrm{CV}$ & 29,69 & -- \\
\hline S10 & $2.4 \mathrm{flex}$ & Gasolina pura & 10,4 & $141 \mathrm{CV}$ & 35,10 & 0 \\
\hline S10 & $2.4 \mathrm{flex}$ & $\begin{array}{c}\text { Gasolina } \\
\text { brasileira } \\
(23 \% \text { etanol })\end{array}$ & 9,5 & $141 \mathrm{CV}$ & 28,62 & 18 \\
\hline S10 & 2.4 flex & Etanol (cana) & 7,2 & $147 \mathrm{CV}$ & 6,92 & 80 \\
\hline
\end{tabular}

*Todos os modelos são cabine simples. Fonte: Soares et. al., 2009

Com base na tabela acima calcula-se a emissão de GEEs para os $14 \mathrm{~km}$ da rodovia SP-613 que secciona o PEMD:

1 veículo a diesel emite $4,15 \mathrm{KgCO}_{2 \text { equiv. }}$

1 veículo à gasolina brasileira emite $4,0068 \mathrm{KgCO}_{2 \text { equiv. }}$

1 veículo a etanol emite $0,9688 \mathrm{KgCO}_{2 \text { equiv. }}$

Considerando que transitam, em média, 2.000 veículos por dia na SP-613 (dados observados nas campanhas educativas do PEMD), hipoteticamente circulariam: 500 a diesel, 500 a gasolina, 1.000 bicombustível, resultando os seguintes valores anuais:

500 veículos a diesel:

Emissões de GEEs por veículos a diesel, no trecho de 14 km (SP613) é igual a $2.075 \mathrm{KgCO}_{\text {2equiv. }} /$ dia, então em 1 ano, teríamos: $757.375 \mathrm{KgCO}_{2 \text { equiv. }}$

500 veículos à gasolina brasileira:

Emissões de GEEs por veículos a gasolina, no trecho de $14 \mathrm{~km}$ (SP613) é igual a $2.003,4 \mathrm{KgCO}_{2 \text { equiv. }} /$ dia, então em 1 ano, teríamos: $731.241 \mathrm{KgCO}_{2 \text { equiv. }}$

\subsection{0 veículos a etanol:}

Emissões de GEEs por veículos a etanol, no trecho de $14 \mathrm{~km}$ (SP613) é igual a $968,8 \mathrm{KgCO}_{2 \text { equiv. }} /$ dia, então em 1 ano, teríamos: $353.612 \mathrm{KgCO}_{2 \text { equiv. }}$

Considerando que 1 hectare com 1.667 mudas de árvores fixa 80 toneladas de $\mathrm{CO}_{2}$ em 1 ano (ASEC/SMA, 2007), então a compensação por ano seria: 
Veículos a diesel = 9,467 hectares com o plantio de 15.782 árvores por ano.

Veículos a gasolina brasileira $=9,14$ hectares com o plantio de 15.237 árvores por ano.

Veículos a etanol $=4,42$ hectares com o plantio de 7.368 árvores por ano.

TOTAL $=38.387$ árvores plantadas/ano ou 22 ha/ano

Estes cálculos demonstram como a conservação sistemática e periódica dos aceiros corta fogo nas margens da estrada é importante para a manutenção da floresta do Parque e seus estoques de carbono imobilizado; ou o valor anual de compensação ambiental referente a 22 hectares de florestas plantadas para mitigar as emissões no trecho, um mínimo de $\mathrm{R} \$ 112.900,00 /$ ano considerando-se $\mathrm{R} \$ 5.000,00$ o hectare.

\section{Considerações Finais}

Passados doze anos de publicarmos um artigo sobre este mesmo assunto e 23 anos de iniciadas as ações de gestão em prol de solucionar os impactos da rodovia sobre o parque, a pretensão deste trabalho foi atualizar e apresentar os fatos ocorridos neste interregno. A SP-613 dentro do parque começou a se transformar lentamente de uma ameaça real a uma oportunidade para o aprendizado coletivo e mais um atrativo turístico para o município de Teodoro Sampaio. Guardas-parque observaram grupos familiares passeando e tirando fotos junto a essas instalações, permitindo inferir sobre o provimento de mais orgulho à população local e aumento da inserção do parque no destino do desenvolvimento sócio econômico regional.

Mas duas décadas não foram suficientes para dar completa solução ao problema; e certamente se o Ministério Público não tivesse assumido a frente dessa questão as tratativas entre as organizações públicas responsáveis pelo parque e pela rodovia provavelmente estariam ainda em seus primórdios.

Os desdobramentos administrativos a partir da edição do Decreto №53.146 foram bastante significativos e resultaram em um Plano de Implantação e um Plano de Operações, ambos edificados entre FF e DER com a oitiva do Conselho Consultivo do parque. As metas e atividades listadas no quadro 3 deverão ser alvos prioritários para a 
gestão eficaz da UC, ainda que as medidas adotadas até agora tenham feito reduzir os atropelamentos em cerca de $40 \%$.

Mas o tempo decorrido para que as primeiras medidas fossem tomadas com seriedade demonstra cabalmente que apesar de as soluções existirem, elas são difíceis de serem plenamente alcançadas, muitas vezes por falta de visão ou esclarecimento dos tomadores de decisão nos diferentes níveis de governo, o que infelizmente faz reverberar o velho antagonismo entre a conservação da natureza e o desenvolvimento socioeconômico.

Impossível um mundo sem caminhos, estradas e rodovias, inimaginável. Mas a construção e operação delas no interior de ambientes naturais causa impactos negativos persistentes, hoje conhecidos pela ciência e reportados por ampla literatura especifica. Dependendo das circunstâncias e condições a que estão submetidos os componentes da biota, e a freqüência e a magnitude das perturbações, os impactos podem passar a irreversíveis, como o cenário delineado para a população de Tapirus terrestris do PEMD.

Hoje as unidades de conservação de proteção integral paulistas contam com um poderoso instrumento de trabalho que é o Decreto $\mathrm{N}^{0}$ 53.146. Na atualidade o 'programa estrada parque' da Fundação Florestal está inserido no Núcleo de Ecoturismo, bastante pertinente, mas aparenta sofrer seus reveses e se encontra moroso, esquecido ou na 'geladeira'. Dado a quantidade de UCs com rodovias públicas em São Paulo, urge que a SMA retome as origens deste programa e, juntamente com a Secretaria de Transportes e DER tenham novidades a mostrar aos contribuintes e aos turistas em 2014, ano da Copa do mundo de Futebol no Brasil. Há que se trabalhar!

São Paulo não conta com um sistema de unidades de conservação estabelecido ordeiramente como outros estados fizeram a partir do advento do SNUC. O que São Paulo possui é um Sistema Estadual de Florestas - SIEFLOR, que na verdade trata de estabelecer um novo arranjo organizacional para responder pela gestão e pesquisa nas unidades de conservação, o que ainda está sendo provado.

Por outro lado, o estado não possui apenas áreas protegidas terrestres e, sendo assim, quando chegar o momento de produzir um Plano de Sistema para as UCs paulistas as equipes de planejamento devem ter em mente a oportunidade de ser instituída a categoria "estrada-parque"; não para aumentar a superfície protegida, mesmo 
porque haveria muitas sobreposições, mas para garantir a continuidade e intensificar uma política pública acertada, assegurando maior atenção da sociedade e das organizações ambientais para as belas paisagens avistadas dos veículos que trafegam em nossas unidades de conservação.

\section{Reconhecimentos}

Os funcionários do Parque Estadual do Morro do Diabo pela coleta dos dados de monitoramento. O Promotor de Justiça e Meio Ambiente Dr. Nelson R. Bugalho, por acolher a questão ambiental e insistir na busca de resultados positivos. Os membros do Conselho Consultivo e demais cidadãos envolvidos nas discussões. Os senhores Francisco Graziano Neto e Jose Amaral Wagner Neto, que estando respectivamente Secretário do Meio Ambiente e Diretor Executivo da Fundação Florestal à época, conheceram o problema e com suas equipes edificaram uma valorosa ferramenta para a gestão de rodovias inseridas em unidades de conservação de São Paulo.

\section{Referências}

Amaranthus, M. P., Rice, M. R., Barr, N. R. e Ziemer, R. R. 1985. Logging and forest roads related to increased debris slides in Southwestern Oregon. J. For. p.229-233.

Araujo, E. e Barreto, P. Ameaças formais contra as Áreas Protegidas na Amazônia. IMAZON. http://www.imazon.org.br/publicacoes/o-estado-da-amazonia/ameacas-formais-contra-as-areasprotegidas-na acessado em 15/01/2012

Araujo, R. M. P. de. 2001. Estrada-Parque Pantanal: uma ferramenta de conservação da biodiversidade pantaneira. Dissertação de Mestrado em Gestão e Política Ambiental, UnB-CDS: Brasília.

Brasil. Lei Federal no. 9.985, de 18 de julho de 2000. Diário Oficial da União, 2000. P 1-6, 19 de jul. de 2000.Seção I. Regulamenta o artigo 225, $1^{\circ}$ - incisos I, II, III e IV da Constituição Federal, institui o Sistema Nacional de Unidades de Conservação da Natureza e dá outras providências.

Cândido-Jr, J. F.; Margarido, V. P.; Pegoraro, J. L.; D'Amico, A. R.; Madeira, W. D.; Casale, V.C.; Andrade, L. 2002. Animais atropelados na rodovia que margeia o Parque Nacional do Iguaçu, Paraná, Brasil, e seu aproveitamento para estudos da biologia da conservação. Anais do III Brasileiro de Unidades de Conservação, Fortaleza, Brasil.p.553-562. 
Cherem, J. J.; Kammers, M.; Ghizoni-JR., I. R.; Martins, A. 2007. Mamíferos de médio e grande porte atropelados em rodovias do Estado de Santa Catarina, Sul do Brasil. Biotemas. 20 (2): 81 96.

Chizzotti, Antônio. Pesquisa em ciências humana e sociais. $7^{\text {ạ }}$ ed. São Paulo: Cortez, 2005.

Clevenger, A. P. e Waltho, N. 2000. Factor influending the efectiveness of wildlife underpasses in Banff National Park, Alberta, Canada. Conservation Biology. 14(1): 47-56.

Departamento de Estradas de Rodagem. 2008. Estudo ambiental para solicitação de licença de operação regularizadora. Rodovia Arlindo Bétio (SP 613), Km 0+000 ao Km 93+800. Teodoro Sampaio / Euclides da Cunha Paulista / Rosana. DER/Assessoria Ambiental. São Paulo, SP. 66 p.

Diário Oficial do Estado. 2011. Resolução conjunta SMA/SLT nำ1, de 20 de julho de 2011. Dispõe sobre a implementação dos Planos de Implantação e Operação da Rodovia Arlindo Bétio (SP613), de acordo com o Decreto Estadual no 53.146, de 20 de junho de 2018. Processo FF 947/2011. Vol. I. Fundação Florestal. Secretaria de Meio Ambiente. D.O.E. de São Paulo. Seção I, páginas 66-67.

Diegues, Antônio Carlos Sant'Ana. O Mito Moderno da Natureza Intocada. São Paulo: Editora Hucitec, 1996. 169p.

DNIT/IME - Projeto de Ampliação da Capacidade Rodoviária das ligações com os países do MERCOSUL BR 101 Florianópolis (SC)-Osório (RS).

Dourojeanni, M. J. Análise crítica dos planos de manejo de áreas protegidas no Brasil. In: BAGER, A. (Ed.). Áreas protegidas: conservação no âmbito do Cone Sul. Pelotas: Ed. Universidade Católica de Pelotas, 2003. p. 1-20.

Faria, H. H. de, Pires, A. S. \& Zanchetta, D. 2005. Unidades de Conservação ameaçadas ou organização com problemas? O caso de UCs do Estado de São Paulo. 3ํ Simpósio de Áreas Protegidas. 16 a 20 de outubro de 2005. Pelotas, RS. CD-ROM 3 CDD577.098.

Faria, H. H. de; Pires, A. S. 2007. Gestão de Unidades de Conservação: Conceituação e Componentes Básicos para a Excelência do Processo. Anais do V Congresso Brasileiro de Unidades de Conservação. Fundação O Boticário de Proteção à Natureza. 17 a 21 de junho de 2007. Foz do Iguaçu, Brasil. Pg. 54 c/ CD ROM. ISSS 1677-1486.

Faria, H.H. e Moreni, P.D.C. 2000. Estradas em unidades de conservação: impactos e gestão no Parque Estadual do Morro do Diabo, Teodoro Sampaio, SP. In II Congresso Brasileiro de Unidades de Conservação. Campo Grande, MS. 05 a 09 de novembro de 2000. p. 761-769.

Formam, R.T.T., Alexander, L.E. 1998. Roads and their major ecological effects. Annual Review Ecological Systems. 29:207-231.

Forman, T. T. R. \& Deblinger, D. R. 2000. The Ecological Road-Effect Zone of a Massachusetts (U.S.A.) Suburban highway. In Conservation Biology. 14(1): 36-46.

Forman, T. T. R. 2000. Estimate of the Area Effected Ecologically by the Road System in the United States . In Conservation Biology. (1) 14: 31-35.

Freire, R. B.; Mello, V. de M. 2008. Impactos ambientais causados pela rodovia Arlindo Bétio (SP 613) no Parque estadual do Morro do Diabo. Trabalho de Conclusão de Curso. Engenharia Ambiental. Universidade Estadual Paulista. Presidente Prudente, SP. 112 p.

Garrido, M.A. de O. 1975. Estrada de Parque Nacional. Instituto Florestal de São Paulo, IF. Relatório de viagem técnica ao Japão. 6p. 
Hahn, C. M.; REIS, C. A. M.; Ahmad, I. T.; Leite, S. sd Proposta Metodológica para Valoração de Danos Ambientais. Coordenadoria de Proteção dos Recursos Ambientais. Secretaria Estadual do Meio Ambiente. São Paulo.

Haskell, G. D. 2000. Effects os Forest Roads on Macroinvertebrate Soil Fauna of the Sourthen Appalachian Mountains. In Conservation Biology. 14(1): 18-30.

IBAMA. 1992. Lista Oficial de espécies brasileiras ameaçadas de extinção. Portarias $n^{\circ} 1.522$, de 19 de dezembro de 1.989 e da Portaria no $45-\mathrm{N}$, de 27 de abril de 1.992.

Instituto Florestal. 2006. Parque Estadual do Morro do Diabo - Plano de Manejo. Coord. Editorial Helder Henrique de Faria e Andréa Soares Pires. Vários autores. Instituto Florestal. Secretaria de Estado de Meio Ambiente. Editora Viena. Santa Cruz do Rio Pardo, SP. 2006. 311 p.

Jochimsen, D. M. Factors influencing the road mortality of snakes on the Upper Snake River Plain, Idaho. 2006. In Proceedings of the 2005 International Conference on Ecology and transportation, Eds. Irwin C.L., Garret P., McDermott K. P. Center of Transportation and the Environment, North Carolina State University, Releigh, NC. Pp. 351-365.

Jones, A. J., Swanson J. F., Wemple C. B., Snyder, U.K., 2000. Effects of roads on hydrology, geomorpholy, and disturbance in stream networks. In Conservation Biology. 14:76-85.

Lakatos, Eva Maria; Marconi, Marina de Andrade. Fundamentos da metodologia científica. 6. ed. 7.reimpr. São Paulo: Atlas, 2009.

Lamy, A. C. M.; Leuzinger, M. D.; Pinto, M. O. 2006. Rodovia em Unidade de Conservação: o Caso da Estrada Parque dos Pireneus (GO). III Encontro da ANPPAS. 23 a 26 de maio de 2006. Brasília-DF. www.anppas.org.br/encontro.../TP452-03032006-124319.DOC. acessado em $15 / 04 / 2012$

Leite, J. F. 1998. A Ocupação do Pontal do Paranapanema. São Paulo.Ed. Hucitec. Fundação UNESP. 202p.

Lima, S. F. e Obara, A. T. 2004. Levantamento de animais silvestres atropelados na BR-277 às margens do Parque Nacional do Iguaçu: Subsídios ao programa multidisciplinar de proteção à fauna. In VII Sema de Artes e II Mostra Integrada de Ensino, Pesquisa e Extensão. Universidade Estadual de Maringá. Maringá, PR. 7 p.

Lopes, J.A.U. e Queiroz, S.M.P. 1994. Rodovias e Meio Ambiente no Brasil: uma resenha crítica. Anais do Encontro Nacional sobre recuperação de Áreas degradadas. Curitiba, PR. p.75-84.

Machlis, Gary E. e Neumann, R.P. La situación de los parques nacionales en la región neotropical. IN: Cardich, E. (Ed). Actas de la 27ª sesión de trabajo de la comisión de parques nacionales y de áreas protegidas de la UICN: conservando el patrimonio natural de la región neotropical. Bariloche, Argentina:1986. pp 43-50.

Medici, Emília Patrícia. Assessing the Viability of Lowland Tapir Populations in a Fragmented Landscape. Thesis submitted for the degree of Doctor of Philosophy in Biodiversity Management Durrell Institute of Conservation and Ecology (DICE). University of Kent. Canterbury, United Kingdom. January 2010.

Milli, M. e Passamani, M. 2006. Impacto da Rodovia Josil Espíndula Agostini (ES-259) sobre a mortalidade de animais silvestres (Vertebrata) por atropelamento. Natureza on line 4(2): 40-46. http://www.naturezaonline.com.br

Oeste Noticias. DER terá que implementar ações de conservação no Morro do Diabo. 24 de março de 2009. Caderno 2. Pág. 8. 
Olmos, F. 1996. Impacto sobre a fauna: Ampliação da capacidade rodoviária entre São Paulo e Florianópolis (BR 116/SP/PR) - Transposição da Serra do Cafezal - DNER/IME. São Paulo, Instituto Florestal.

Padua, C.V.; Cullen Jr., L. e Padua, S. 1995. Threats of roads to wildlife. Neotropical Primates. 3(1): 14-15.

Padua, M.T. J.; Porto, E. L. R.; Borges, G. C.; Bezerra, M. M. L. 1982. Plano do Sistema de Unidades de Conservação do Brasil - II Etapa. Ministério da Agricultura. IBDF/FBCN. Brasil. 173 p.

Parendes, A.L.e Jones, A. J. 2000. Role of Liht Availability and Dispersal in Exotic Plant Invasion along Roads in the H.J. Andrews Experimental Forest, Oregon. In Conservation Biology. 14(1): 6475.

Peña, A.P.; Drumond, M.E. 1999. Levantamento de vertebrados mortos por atropelamento na rodovia GO-244 - Área de influência do projeto de irrigação "Luiz Alves do Araguaia". Relatório apresentado ao Ibama.

Pereira, G. F. P. A.; Andrade, G. A. F.; Fernandes, B. E. M. 2006. Dois anos de monitoramento dos atropelamentos de mamíferos na rodovia PA-458, Bragança, Pará. Museu de Biologia Emílio Goeldi, (3): 77-83.

Philcox, C.K.; Grogan, A.L.; Macdonald, D.W. Patterns of otter Lutra lutra road mortality in britain. Biological Conservation, 36: 748-762, 1999.

Prado, T. R.; Ferreira, A.A.; Guimarães, Z. F. S. 2006. Efeito da implantação de rodovias no cerrado brasileiro sobre a fauna de vertebrados. Acta Sci. Biol. Sci. v. 28, n. 3, p. 237-241.

Projeto Básico Ambiental-PBA, 2004. Subprograma de Proteção à Fauna. Disponível: http://dnit.ime.eb.br/br163/pba/prog_prote_fauna_flora.pdf. Acesso: agosto de 2007.

Rocha, S.B. e Correa, M.C. 1998. Uma ferida aberta. Revista Horizonte Geográfico. Ed. especial. 60 Anos de Parques Nacionais. Audichromo-Editora. p.20-21.

Rodrigues, F. H. G.; Hass, A.; Rezende, L. M.; Pereira, C. S.; Figueiredo, C. F.; Leite, B. F.; França, F. G. R. 2002. Impacto de rodovias sobre a fauna da Estação Ecológica de Água Emendadas, DF. Anais do III Congresso Brasileiro de Unidades de Conservação, Fortaleza, Brasil. p.585-593.

Rosa, O.; Mauhs, J. 2004. Atropelamentos de animais silvestres na rodovia RS - 040. Caderno de Pesquisa, Série Biologia, 16: 35-42.

Sánchez, L.E. Avaliação de impacto ambiental: conceitos e métodos. Oficina de Textos. São Paulo, 2006. p32.

Santos, L. R.; Cavalcanti, R. B. (2004). Revisão de estudos sobre a dispersão de fauna em paisagens fragmentadas de Cerrado para modelos de simulação. Anais do XXV Congresso Brasileiro de Zoologia, 1761, 445p.

Santos, Rosely Ferreira. Planejamneto Ambiental: Teoría e prática. Ed. Oficina de Textos. 2004. $184 \mathrm{p}$.

Schonewald-Cox, C. e Buechner, M. 1991. Park protection and public roads. In Conservation Biology. Ed. Fielder, P.L. e Jain, S.K. p.375-395

Scoss, L. M. 2002. Impacto de estradas sobre mamíferos terrestres: O caso do Parque Estadual do Rio Doce, Minas Gerais. Dissertação de Mestrado. Programa de Pós Graduação em Ciencias Florestais. Universidade Federal de Viçosa. $97 \mathrm{p}$. 
Scoss, L. M.; Junior, P.M.. Estradas no Parque: Efeitos da Fragmentação Interna Sobre a Intensidade de Uso do Habitat Por Mamíferos Terrestres. In: II CONGRESSO BRASILEIRO DE UNIDADES DE CONSERVAÇÃO-2., Campo GrandeMS. Anais Vol. II Trabalhos Técnicos. 2000.

Secretaria de Meio Ambiente de Mato Grosso. 2007. Plano de Manejo da Estrada Parque Santo Antônio de Leverger-Porto de Fora- Barão de Melgaço (Rodovia MT - 040/361). Vários autores. $132 \mathrm{p}$.

Silva, M. O.; Oliveira, I. S.; Cardoso, M. W.; Graf, V. 2007. Impacto dos atropelamentos sobre a herpetofauna da Floresta Atlântica (PR-340, Antonina, Paraná). Acta Biológica Paranaense.36 (12): 103-112.

Smith, L.L.; Dodd Jr, C.K. 2003. Wildlife mortality on U.S. highway 441 across paynes prairie, Alachua County, Florida. Florida Scientist, 66(2): 128-140.

Soares, L.H.B; Alves, B.J.R; Urquiaga, S. e Boddey, R.M. 2009. Mitigação das Emissões do Efeito Estufa pelo Uso do Etanol da Cana-de-Açucar Produzido no Brasil. Circular Técnica. EMBRAPA. Seropédica, RJ.

Trombulak, C. S. e Frissel, A. C. 2000. Review of Ecological Effects of Roads on Terrestrial and Aquatic Communities. In Conservation Biology. 14(1): 18-30.

Turci, L. C. B. \& Bernarde, P. S. 2009. Vertebrados atropelados na Rodovia Estadual 383 em Rondônia, Brasil. Biotemas, 22 (1): 121-127, março de 2009.

UICN. Parques e Progresso. UICN. Ed. por Valerie Barzetti. Trad. por Leonor y Yanina Rovinski. Washington, D.C. USA: 1993. 258p.

Valladares-Padua, C.; Cullen Jr, M. L.; Padua, S. 1995. A pole bridge to avoid primate road kills. Neotropical Primates, 3 (1): 13-15.

Van Der Zande, A.N.; Ter Keurs, W.J. e Van Der Weiden, W.J. 1980. The impact of roads on the densities of four bird species in a open field habitat: Evidence of a long-distance effect. In Biology Conservation. 18: 299-321.

Vieira, E. M. 1996. Highway mortality of mammals in Central Brazil. Ciência e Cultura. 48: 270272. 